\title{
The Role of Perceived Social Support to Predict Depressive Disorder and Lifestyle Components in Patients with Myocardial Infarction
}

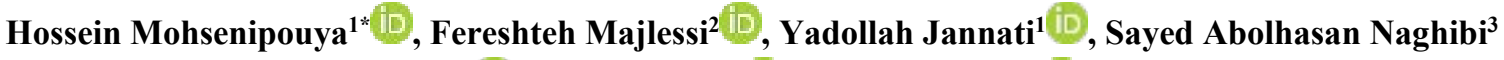 \\ Ali Ghaemian ${ }^{4}$ (D) Alireza Sangani ${ }^{5}$ it \\ 1. Dept. of Nursing, Faculty of Nursing, Mazandaran University of Medical Sciences, Sari, Iran. \\ 2. Dept. of Health Education and Promotion, School of Public Health, Tehran University of Medical Sciences, Tehran, \\ Iran. \\ 3. Health Sciences Research Center, Mazandaran University of Medical Sciences, Sari, Iran. \\ 4. Dept. of Cardiology, Faculty of Medicine, Cardiovascular Research Center, Mazandaran University of Medical \\ Sciences, Sari, Iran. \\ 5. Dept. of Psychology, Ahvaz Branch, Islamic Azad University, Ahvaz, Iran
}

\begin{tabular}{c} 
Article Info \\
\hline dof 10.30699/jambs.29.135.223 \\
\hline Received: $2020 / 07 / 24 ;$ \\
Accepted: $2021 / 02 / 22 ;$ \\
Published Online: 28 Feb $2021 ;$ \\
Use your device to scan and read the \\
article online \\
口.
\end{tabular}

Corresponding Information: Hossein Mohsenipouya,

Dept. of Nursing, Faculty of Nursing, Mazandaran University of Medical Sciences, Sari, Iran

E-Mail::

hosseinmohsenipouya@gmail.com

\begin{abstract}
Background \& Objective: Social support is generally accepted to act as a protective factor against stressful situations. However, the extent of its effect on the depression and lifestyle of myocardial infarction (MI) patients is not known. Therefore, the present study aimed to examine the role of perceived social support in predicting major depressive disorder and lifestyle components in MI patients.
\end{abstract}

Materials \& Methods: This quasi-experimental study was conducted in 2019 on 176 MI patients chosen through the purposive and convenience sampling methods from the Heart Center Hospital of Mazandaran, Iran. The required information was collected by three standard questionnaires, including the social support appraisals (SSA) scale by Phillips, the Beck Depression Inventory (BDI-II), and Health-Promoting Lifestyle Profile (HPLP-II). Pearson correlation coefficient and canonical correlation coefficient were performed. The significance level in this study was considered as Pvalue $<0.05$.

Results: The findings of the present study indicated that social support could predict depression by $48 \%$ and a significant negative correlation was found between social support and depression $(\mathrm{r}=-0.47, P=0.01)$. Moreover, social support had a significant impact on lifestyle components and was shown to predict health accountability $\left(\mathrm{R}^{2}=0.691, \beta=0.289\right)$, spiritual growth $\left(\mathrm{R}^{2}=0.672, \beta=0.256\right)$, stress management $\left(R^{2}=0.285, \beta=0.122\right)$, and interpersonal behavior $\left(R^{2}=0.586, \beta=0.175\right)$. In addition, it affected these factors significantly.

Conclusion: Providing opportunities for further social support for MI patients paves the way for enhancing health-promoting behaviors and reducing depression in this group of patients.

Keywords: Depression, Lifestyle, Myocardial Infarction (MI), Perceived social support

\section{Introduction}

Depression, as a prevalent mental health disorder worldwide, plays a critical role in enhancing the global burden of diseases (1). Major depressive disorder (MDD) is a mood disorder characterized by a persistent feeling of low mood, loss of pleasure and interest, weight loss, insomnia, fatigue, emptiness, psychomotor slowness, guilt, diminished concentration, and the recurrent thoughts of death (2).

Among mental disorders, MDD accounts for the largest portion $(40.5 \%)$ of disability-adjusted life years (DALYs)
(3). In Asia, the prevalence of depression is estimated to be about $7.8 \%-34.8 \%$ in adults (4). In general, more than 300 million individuals of different ages suffer from this disorder (5). According to the reports, one-fifth of Iranians are affected by depression. A national study on the burden of diseases and injuries indicated that mental illnesses and behavioral disorders are the second leading cause of health problems in Iran. In addition to intentional and unintentional incidents, depression is the third most prevalent health problem in the country. 
Considering the relatively high prevalence of depression and the significant burden of this disease for patients, health systems, and societies, further studies are recommended for adopting appropriate treatment approaches, prevention measures, and management practices (6). Although the risk factors of depression are well detected, the preventive factors have less been researched (3). Social support is introduced as one of these effective factors. The concept of social protection means protecting people from mental health problems and works through the benefits of social relationships as a protective shield against stressful situations (1). In addition to physical problems, cardiovascular patients face psychological problems, such as anxiety and depression. As a result, understanding the relationship between disease perception and disease outcomes can affect the quality of life in patients (7).

Depression is one of the major medical and social problems, which is considered the most common comorbid disorder in many medical conditions, especially heart disease (8). Some studies have revealed a significant relationship between depression and perceived social support in patients with heart disorders (9-12). Bucholz et al. showed that the low levels of social support in myocardial infarction (MI) patients were associated with a poor health condition and higher levels of depression (13). Leifheit-Limson et al. also concluded that cases with less social support had a lower mental function and revealed more depressive symptoms during 12 months, in comparison to the patients receiving higher support (14).

However, the exact relationship between social support and depression is still unknown (15). In a clinical trial, a negative relationship was found between depression and social support, which may be due to the social support of friends rather than family. It is a fact that social support by friends is more understood among younger individuals (16). This finding suggests that the specific domain of social support plays a vital role in improving or diminishing depression (15).

Moreover, previous studies have indicated that negative statements and the lack of social qualification exhibited by depressed patients may disrupt their social relationships $(17,18)$. Moreover, it is proved that depressed and susceptible people develop negative responses and have problems in interactions with others making others stay away from them (16). The results of an epidemiological study indicated that a healthy lifestyle, such as having a proper diet, not smoking, maintaining an ideal weight, and physical activity can be effective in controlling cardiovascular risk factors (19).

This survey was designed due to the lack of a precise relationship between social support and depression (1518) and the value and social importance of (15-18) and the value and social support importance. . The cited resource may be very helpful for cardiovascular patients to tackle their psychological and physical problems. Therefore, the present study aimed to assess the role of perceived social support in predicting MDD and lifestyle components in MI patients.

\section{Materials and Methods}

This quasi-experimental study was conducted on MI patients of Mazandaran Heart Center Hospital, Iran in 2019. This study was approved by the Ethics Committee of Mazandaran University of Medical Sciences with the code of NO.IR.MAZUMS.REC.13971105. To follow the research ethics, a letter of introduction was obtained from the research deputy of Mazandaran University of Medical Sciences and was submitted to the head of Mazandaran Heart Center Hospital.

Following being introduced to the study participants, the research objectives were explained to them. The subjects were informed that participation in the study was voluntary and the consent forms were signed. To ensure the confidentiality of the collected data, the names of patients were not written on the information sheets.

In this study, purposive and convenience sampling methods were adopted. The sample size was considered as 176 patients based on the sample size formula. The inclusion criteria were willingness to participate in this study, the lack of emergency conditions, full consciousness at research time, no previous history of depression according to the recorded documents and the history of the patient, and at least five days being passed from cardiac infarction. The exclusion criteria entailed unwillingness to participate in this study and serious emergency conditions. The sample size was estimated based on the results of the study carried out by LeifheitLimson (14) and the following equation:

$$
n=\frac{\left(z_{\frac{\alpha}{2}}+z_{\beta}\right)^{2} \sigma^{2}}{d^{2}}=176, \sigma=26 \quad d=5 \quad \alpha=0.05, \beta=0.2
$$

Three standard questionnaires were utilized to collect the required data.

\section{Social Support Appraisals (SS-A) Scale by Phillips}

The questionnaire developed by Phillips et al. (1974) contains 23 questions addressing three domains of family, friends, and others. Depending on the environmental conditions in terms of social support, the participants selected yes or no options for each question. The score range of this questionnaire is $0-23$ with items $10,3,13$, 21 , and 22 being scored reversely. The validity and reliability of the questionnaire have been confirmed (20).

\section{Beck Depression Inventory (BDI-II)}

The questionnaire was developed in 1967 and contains 21 questions for assessing diseases. It gives a score of 0 63 and each item has 4-5 options, one of which is selected based on the mood of the patient. This highly reliable inventory is one of the most widely-used tools in measuring depression (21-23). Four options of each question are scored on a four-point scale with the range of 0-3. Each item describes one of the most common signs of anxiety, including mental, physical, and panic 
symptoms. Anxiety level is determined based on the scores as none or minimal (0-7), mild (8-15), moderate (16-25), and severe (26-63) (24).

\section{Health-Promoting Lifestyle Profile (HPLP-II)}

The lifestyle of patients was evaluated using the HPLPII. This questionnaire assesses health-promoting behaviors in six dimensions, namely health accountability, interpersonal behavior, spiritual growth, nutrition, stress management, and physical activity. The total score of this questionnaire is 25-208 and the validity and reliability of this survey have been confirmed in diverse studies $(25,26)$. In the current study, the social support and lifestyle of patients were classified as weak, moderate, and good as the first, second, and third quartiles, respectively $(25 \%, 50 \%, 75 \%)$.

\section{Statistics Analysis}

The data were collected from the files and direct interviews of patients and were analyzed using the SPSS software version 23 (IBM, Ill., USA). Descriptive statistics, including the mean and standard deviation were used to describe the data for quantitative variables, such as social support components and qualitative variables, such as gender. Pearson correlation coefficient and canonical correlation coefficient were employed to analyze the data and evaluate the relationships between the variables. The significance level was considered as Pvalue $<0.05$.

\section{Results}

The mean age of the participants was $12.5 \pm 54.59$ years. The majority $(89.2 \%)$ of the participants were married, $23.3 \%$ were retired, and $37.5 \%$ had elementary education. The mean time interval between MI and interview was $7.5 \pm 0.75$ days. All questionnaires were filled out by patients at the time of hospitalization.

Table 1. Frequency of demographic variables in MI patients

\begin{tabular}{|c|c|c|}
\hline \multicolumn{2}{|c|}{ Variable } & \multirow{2}{*}{$\begin{array}{c}\mathbf{N}(\%) \\
178(72.9)\end{array}$} \\
\hline \multirow{5}{*}{ Marital status } & Male & \\
\hline & Female & $48(27.3)$ \\
\hline & Single & $8(4.6)$ \\
\hline & widow & $11(6.3)$ \\
\hline & Married & 157(89.2) \\
\hline \multirow{6}{*}{ Level of education } & Elementary & $66(37.5)$ \\
\hline & Diploma & $42(23.9)$ \\
\hline & Associate Degree & $15(8.5)$ \\
\hline & $\mathrm{MA} / \mathrm{BS}$ & $19(10.8)$ \\
\hline & MA/MS & $18(10.2)$ \\
\hline & Others & $16(9.1)$ \\
\hline \multirow{6}{*}{ Occupation } & Clerk & $25(14.2)$ \\
\hline & Farmer & $29(16.3)$ \\
\hline & Self-employed & $35(19.9)$ \\
\hline & Retired & $41(23.3)$ \\
\hline & housewife & $38(21.6)$ \\
\hline & Others & $8(4.5)$ \\
\hline
\end{tabular}

Table 2. Mean and standard deviation of lifestyle components, social support and depression in MI patients

\begin{tabular}{ccc} 
Variable & SD \pm & Mean \\
\hline Age & 54.29 & \pm 12.50 \\
\hline Social support & 18.32 & \pm 0.31 \\
Depression & 13.60 & \pm 0.79 \\
\hline lifestyle & 146.47 & \pm 7.01 \\
\hline
\end{tabular}


According to Table 2, the depression level was low (13.6 \pm 0.79$)$ among patients with good social support (18.32 \pm 0.31$)$. Moreover, the lifestyle of patients was moderate $(146.47 \pm 7.01)$.

As could be observed in Table 3 , social support affected lifestyle components significantly. Our findings demonstrated that social support predicted and significantly influenced health accountability $\left(\mathrm{R}^{2}=0.691\right.$, $\beta=0.289)$, spiritual growth $\left(R^{2}=0.672, \beta=0.256\right)$, stress management $\left(\mathrm{R}^{2}=0.285, \beta=0.122\right)$, and interpersonal behavior $\left(R^{2}=0.586, \beta=0.175\right)$.

Table 3. Canonical correlation coefficients in predicting lifestyle components (benchmark variable) regarding to social support (predictive variables)

\begin{tabular}{|c|c|c|c|c|c|c|}
\hline $\begin{array}{l}\text { Independent } \\
\text { variable }\end{array}$ & $\begin{array}{l}\text { Canonical } \\
\text { functions }\end{array}$ & $\begin{array}{l}\text { Canonical } \\
\text { correlation }\end{array}$ & $\mathbf{R}^{2}$ & Effect (B) & $\mathbf{t}$ & $\mathbf{p}$ \\
\hline \multirow{6}{*}{ Social support } & $\begin{array}{c}\text { Health } \\
\text { accountability }\end{array}$ & 0.355 & 0.691 & 0.289 & 4.108 & 0.001 \\
\hline & Physical activity & 0.336 & 0.113 & 0.048 & 1.112 & 0.527 \\
\hline & Nutrition & 0.831 & 0.126 & 0.016 & 0.236 & 0.639 \\
\hline & Spiritual growth & 0.534 & 0.672 & 0.256 & 4.844 & 0.001 \\
\hline & Stress management & 0.819 & 0.285 & 0.122 & 2.124 & 0.001 \\
\hline & $\begin{array}{c}\text { Interpersonal } \\
\text { behavior }\end{array}$ & 0.765 & 0.586 & 0.175 & 4.968 & 0.001 \\
\hline
\end{tabular}

Table 4. Mean, standard deviation, and Pearson correlation coefficient matrix for the relationship between social support and depression

\begin{tabular}{ccccc}
\hline variable & M & SD & Perceived stress & Physical symptoms \\
\hline Social support & 16.71 & 2.82 & 1 & 1 \\
\hline Depression & 14.25 & 11.60 & $-0.47^{* *}$ & 1 \\
\hline$* * p \leq 0.01$ & & & &
\end{tabular}

The results summarized in Table 4 indicated an indirect correlation between social support and depression $(\mathrm{r}=-$ $0.47, P<0.01)$. As shown in Table 5, regarding the value of $\mathrm{R}^{2}$, social support could predict depression by 0.479 . Furthermore, the value of $\beta$ indicated that social support imposed a negative effect on depression $(-0.479)$.

Table 5. Multiple correlation coefficient, beta coefficients, determination coefficient, and standard error

\begin{tabular}{|c|c|c|c|c|c|c|c|}
\hline $\begin{array}{l}\text { Predictive } \\
\text { variables }\end{array}$ & $\mathbf{R}$ & $\mathbf{R}^{2}$ & $\begin{array}{c}\text { Adjusted } \\
\text { R- } \\
\text { squared }\end{array}$ & SE & $\begin{array}{c}\text { Coefficient } \\
\text { F }\end{array}$ & Sig. & $\begin{array}{c}\text { Coefficient } \\
\text { of effect }\end{array}$ \\
\hline Social support & 0.479 & 0.229 & 0.214 & 10.292 & 52.326 & 0.001 & -0.479 \\
\hline
\end{tabular}

\section{Discussion}

This study aimed to examine the role of perceived social support in predicting MDD and lifestyle components in MI patients. Our results indicated a statistically significant reverse correlation between the level of social support and depression. The latter finding has been supported by many other studies (2729).

In a study by $\mathrm{Su}$ et al., the correlation between social support and depression was reported to be -0.48 (30) and the value obtained in the present study was -0.47 . Leifheit-Limson et al. concluded that patients with lower social support had lower quality of life and experienced more depressive symptoms (14). The study conducted by Liu showed that social support may act as a flexibility factor against long-term cardiovascular risk, which is related to depression (31).
Compare et al. investigated the roles of social support and depression in cardiovascular patients. These authors reported that depressive symptoms and the lack of social and family supports were associated with disease progression (11).

On the other hand, social support in the present study could predict depression by $47 \%$. Consistent with our findings, the prediction powers were $43.7 \%$ and $42 \%$ in the studies carried out by $\mathrm{Su}(30)$ and Miller (21), respectively. These findings would help clinical staff to understand the physical and mental problems of cardiovascular patients. Accordingly, we suggest that the early prediction of depression and adequate social support may improve the conditions of patients in the face of disease and promote the quality of health care services. 
To sum up, social support is an available potential resource, which can be strengthened and bring benefits to individuals. In this regard, the critical role of the family should be taken into consideration. Family can act as an information source with instrumental and emotional supports that reduce the depression symptoms in patients. Therefore, we recommend further investigations and researches about social support and its components.

According to the findings of this study, social support had a significant effect on lifestyle components. It predicted lifestyle components, including health accountability, spiritual growth, stress management, and interpersonal behavior by $69 \%, 67 \%$, $28 \%$, and $58 \%$, respectively. Roming et al. concluded that low stress, high spirituality, and social support correlated significantly with high and medium levels of quality of life in patients. In other words, spiritual growth and social support are the basic adaptation factors in terms of a better quality of life (22). Furthermore, various studies have indicated a positive and significant correlation between social support and lifestyle $(23,32)$. A study in Thailand on women with cervical cancer showed that social support was effective in lifestyle as one unit increase in social support promoted lifestyle behaviors by 0.7 unit (33).

In contrast, Brooks et al. reported that healthpromoting lifestyle factors did not significantly correlate with perceived social support factors (34). The investigation performed by Brooks aimed to evaluate the relationship of social support and lifestyle habits with weight loss during 18-24 months after obesity surgery. The non-significant relationship between social support and lifestyle might be due to more attention to diet and other lifestyle principles in the first days after treatment. In addition, families provide more support to the patients during the first days, which may cause such a result. However, the lifestyle and family support of patients are gradually disregarded over time. Consequently, it is necessary to highlight the significance of this issue for patients and their families.

\section{Conclusion}

Undoubtedly, lifestyle modification in its general sense, psychologically and physically, can be one of the best ways to prevent the occurrence of various diseases in humans. Fortunately, today, improved public awareness has increasingly caused people to check the health of their lifestyle. Moreover, related clinics and counseling centers are expanding in developed countries.

It should be noted that an augmentation in social supports may lead to reduced depressive symptoms and elevated health-promoting behaviors in patients. It is needed to provide opportunities for further social supports of patients through services and interventions, which improve social skills. Furthermore, healthy lifestyle patterns can be taught to others by holding workshops and effective training courses.

\section{Limitations}

Study limitations included self-report by patients, which may tempt them to present a better picture of their social support, depression, and lifestyle.

\section{Acknowledgments}

we acknowledge the patients who participated in the research. The authors are grateful to the Vice Chancellor for research, Mazandaran University of Medical Science.

\section{Conflict of Interest}

The authors declare no conflicts of interest

\section{References}

1. Gariepy G, Honkaniemi H, Quesnel-Vallee A. Social support and protection from depression: systematic review of current findings in Western countries. Br J Psychiatr. 2016;209(4):284-93. [DOI:10.1192/bjp.bp.115.169094]

2. Smolderen KG, Buchanan DM, Gosch K, et al. Depression treatment and 1-year mortality after acute myocardial infarction: insights from the TRIUMPH registry (Translational Research Investigating Underlying Disparities in Acute Myocardial Infarction Patients' Health Status). Circulation. 2017;135(18):1681-9. [DOI:10.1161/CIRCULATIONAHA.116.02514 ㄱ]

3. Whiteford HA, Degenhardt L, Rehm J, et al. Global burden of disease attributable to mental and substance use disorders: findings from the Global Burden of Disease Study 2010. Lancet.2013;382(9904):1575-86. [DOI:10.1016/S0140-6736(13)61611-6]

4. Mohd TAMT, Yunus RM, Hairi F, Hairi NN, Choo WY. Social support and depression among community dwelling older adults in Asia: a systematic review. BMJ Open. 2019;9(7):e026667 [DOI:10.1136/bmjopen2018-026667]

5. Guidi J, Rafanelli C, Roncuzzi R, Sirri L, Fava GA. Assessing psychological factors affecting medical conditions: comparison between different proposals. Gen Hospital Psychiatr. 2013;35(2):141-6. [DOI:10.1016/j.genhosppsych.2012.09.007]

6. Ali Montazeri, Seyed Javad Mousavi, Sepideh Omidvari, Mahmood Tavousi, Akram Hashemi, 
Tahereh Rostami. Depression in Iran: a systematic review of the literature (2000-2010). Health Monitor J Iran Inst Health Sci Res. 2013;12(6):567-94

7. Parsamehr M, Afshani A, Nikoo F. Relationship between anxiety and depression with quality of life after coronary artery bypass graft. Iran J Nurs. 2015;28(93):106-17.

[DOI:10.29252/ijn.28.93.94.106]

8. Cohen BE, Edmondson D, Kronish IM. State of the art review: depression, stress, anxiety, and cardiovascular disease. Am J Hyperten. 2015;28(11):1295-302.

[DOI:10.1093/ajh/hpv047]

9. Kuper H, Marmot M, Hemingway H. 2002. Systematic review of prospective cohort studies of psychosocial factors in the etiology and prognosis of coronary heart disease. In Seminars in vascular medicine . Thieme Medical Publishers. 2002;2(3):267-314 [DOI:10.1055/s2002-35401]

10. Staniute M, Brozaitiene J, Bunevicius R. Effects of social support and stressful life events on health-related quality of life in coronary artery disease patients. J Cardiovasc Nurs. 2013;28(1):83-9.

\section{[DOI:10.1097/JCN.0b013e318233e69d]}

11. Compare A, Zarbo C, Manzoni G, et al. Social support, depression, and heart disease: a ten year literature review. Front Psychol. 2013;1(4):384 [DOI:10.3389/fpsyg.2013.00384]

12. Frasure-Smith N, Lespérance F, Gravel G, et al. Social support, depression, and mortality during the first year after myocardial infarction. Circulation. 2000;101(16):1919-24. [DOI:10.1161/01.CIR.101.16.1919]

13. Bucholz EM, Strait KM, Dreyer RP, et al. Effect of low perceived social support on health outcomes in young patients with acute myocardial infarction: results from the VIRGO (Variation in Recovery: Role of Gender on Outcomes of Young AMI Patients) study. J Am Heart Assoc. 2014;3(5):e001252. [DOI:10.1161/JAHA.114.001252]

14. Leifheit-Limson EC, Reid KJ, Kasl SV, et al. The role of social support in health status and depressive symptoms after acute myocardial infarction: evidence for a stronger relationship among women. Circ Cardiovas Qual Outcomes. 2010;3(2):143-50

[DOI:10.1161/CIRCOUTCOMES.109.899815]

15. Ren $\mathrm{P}$, Qin X, Zhang $\mathrm{Y}$, Zhang R. Is social support a cause or consequence of depression? A longitudinal study of adolescents. Front Psychol. 2018;4(9):1634 [DOI:10.3389/fpsyg.2018.01634]
16. Stice E, Rohde P, Gau J, Ochner C. Relation of depression to perceived social support: Results from a randomized adolescent depression prevention trial. Behav Res Ther. 2011;49(5):361-6. doi: 10.1016/j.brat.2011.02.009 [DOI:10.1016/i.brat.2011.02.009]

17. Joiner Jr TE. Depression in its interpersonal context. 2002.

18. Rudolph KD, Flynn M, Abaied JL. A developmental perspective on interpersonal theories of youth depression. 2008;4(9):79-102.

19. Liu K, Daviglus ML, Loria CM, et al. Healthy lifestyle through young adulthood and the presence of low cardiovascular disease risk profile in middle age: the coronary artery risk development in (Young) adults (CARDIA) study. Circulation. 2012;125(8):996-1004 [DOI:10.1161/CIRCULATIONAHA.111.06068 1]

20. Vaux A, Phillips J, Holly L, Thomson B, Williams D, Stewart D. The social support appraisals (SS-A) scale: Studies of reliability and validity. Am J Comm Psychol. 1986;14(2):195218. [DOI:10.1007/BF00911821]

21. Miller KJ, Mesagno C, McLaren S, Grace F, Yates M, Gomez R. Exercise, mood, selfefficacy, and social support as predictors of depressive symptoms in older adults: Direct and interaction effects. Front Psychol.2019;10(11):111. [DOI:10.3389/fpsyg.2019.02145]

22. Roming S, Howard K. Coping with stress in college: an examination of spirituality, social support, and quality of life. Mental Health, Religion \& Culture. 2019;22(8):832-43. [DOI:10.1080/13674676.2019.1674794]

23. Javadifar N, Larki A, Javadnoori M, Haghighizadeh $\mathrm{MH}$. The relationship between perceived social support and lifestyle in middleaged females of Ahvaz, Iran. Jundishapur J Chron Disease Care. 2017;6(1):1-6. [DOI:10.17795/jicdc-37111]

24. Steer RA, Brown GK, Beck AT, Sanderson WC. Mean beck depression inventory-II scores by severity of major depressive episode. Psychol Reports. 2001;88(3):1075-6. [DOI:10.2466/PR0.88.3.1075-1076]

25. Mohammadi Zeidi I, Pakpour Hajiagha A, Mohammadi Zeidi B. Reliability and validity of persian version of the health-promoting lifestyle profile. J Mazandaran Univ Med Sci. 2012;21(1):102-13

26. Pinar R, Celik R, Bahcecik N. Reliability and construct validity of the health-promoting lifestyle profile II in an adult Turkish population. 


\section{Nurs $\quad$ Res. 2009;58(3):184-93. [DOI:10.1097/NNR.0b013e31819a8248]}

27. Elsayed E, El-Etreby RR, Ibrahim AA-W. Relationship between social support, loneliness, and depression among elderly people. Int J Nurs Didactics. 2019;9(1):39-47. [DOI:10.15520/ijnd.v9i01.2412]

28. Chen L, Alston M, Guo W. The influence of social support on loneliness and depression among older elderly people in China: Coping styles as mediators. J Comm Psychol. 2019;47(5):1235-45. [DOI:10.1002/jcop.22185]

29. Kong LN, Hu P, Yao Y, Zhao QH. Social support as a mediator between depression and quality of life in Chinese community-dwelling older adults with chronic disease. Geriatric Nursing. 2019;40(3):252-6.

[DOI:10.1016/j.gerinurse.2018.10.014]

30. Su SF, Chang MY, He CP. Social support, unstable angina, and stroke as predictors of depression in patients with coronary heart disease. J Cardiovasc Nurs. 2018;33(2):179-86. [DOI:10.1097/JCN.0000000000000419]

31. Liu RT, Hernandez EM, Trout ZM, Kleiman EM, Bozzay ML. Depression, social support, and long-term risk for coronary heart disease in a 13- year longitudinal epidemiological study. Psychiatr Res. 2017;251:36-40. [DOI:10.1016/j.psychres.2017.02.010]

32. Tang YY, Chen SP. Health promotion behaviors in Chinese family caregivers of patients with stroke. Health Promot Int.2002;17(4):329-39. [DOI:10.1093/heapro/17.4.329]

33. Taechaboonsermsak P, Kaewkungwal J, Singhasivanon P, Fungladda W, Wilailak S. Causal relationship between health promoting behavior and quality of life in cervical cancer patients undergoing radiotherapy. Southeast Asian J Trop Med Pub Health. 2005;36(6):1568.

34. Brooks R, Raelene Z. Bariatric surgery regain and long-term weight loss among women: selfefficacy, social support and health promotion lifestyle behaviors. Published by ProQuest LLC. 2019. . [DOI:10.22371/07.2018.012]

\section{How to Cite This Article:}

Mohsenipouya H, Majlessi F, Jannati Y, Naghibi S A, Ghaemian A, Sangani A. The Role of Perceived Social Support to Predict Depressive Disorder and Lifestyle Components in Patients with Myocardial Infarction. J Adv Med Biomed Res. 2021; 29 (135) :223-229

\section{Download citation:}

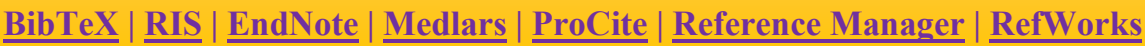

\section{Send citation to:}

Mendeley 2 Zotero 궁 RefWorks RefWorks 